\title{
Improving Argumentative Essay Writing of Saudi English Majors through Adaptive Learning at Shaqra' University
}

\author{
Samah Ahmed Mohammed Elborolosy, Raghad Abdulrahman Almujali \\ English Department, Faculty of Science \& Humanities, Shaqra' University, Shaqra, Riyadh, KSA \\ Email:smohmmad@su.edu.sa
}

How to cite this paper: Elborolosy, S. A. M., \& Almujali, R. A. (2020). Improving Argumentative Essay Writing of Saudi English Majors through Adaptive Learning at Shaqra' University. Open Journal of Modern Linguistics, 10, 161-173. https://doi.org/10.4236/ojml.2020.103010

Received: April 24, 2020

Accepted: May 25, 2020

Published: May 28, 2020

Copyright $\odot 2020$ by author(s) and Scientific Research Publishing Inc. This work is licensed under the Creative Commons Attribution International License (CC BY 4.0).

http://creativecommons.org/licenses/by/4.0/ (c) (i) Open Access

\begin{abstract}
The present study was aiming at examining the effect of adaptive learning on improving argumentative essay of English majors students at Shaqra' University, Kingdom of Saudi Arabia. The researchers followed the quasi-experimental approach. The sample of the study was consisted of thirty-six students purposively selected, representing the total of the class. The instruments of the study were the pre-posttest, adaptive learning questionnaire and a follow-up interview. The data was analyzed statistically using SPSS. The results indicated that there was a difference in writing argumentative essay of the posttest in favor of the experimental group due to adaptive learning. Moreover, the results of the questionnaire indicated that the students preferred adaptive learning techniques and had positive attitude towards it rather than the traditional methods. Findings proved that adaptive learning was effective in enhancing students' argumentative essay writing.
\end{abstract}

\section{Keywords}

English Majors, Advanced Writing, Adaptive Learning, Argumentative Essay, Saudi Education

\section{Introduction}

Argumentative essay is the highest form of writing and requires complex activities and various skills. Firstly, students need to understand the topic to argue for or against the issue, Secondly, they have to do extensive work to collect ideas through surveys, interviews, and questionnaires to synthesize their essays, beside this, at the sentence level students have to write a concise, well defined and clear statement, at the structure level, students have to follow logical con- 
sequences of events to move between introduction, body development and conclusion using factual and logical examples to convince his/her readers. So that students should have enough data, training and well-planned strategies to argue for or against an issue using rational reasons and logical sequence of ideas. Argumentative essay is a complex cognitive activity in which students have to understand how to organize ideas in logical order, use rational methods and facts, choose the appropriate content that suits the given topic and finally have to handle and master the mechanics of writing such as punctuation, sentence structure, and spelling.

Teachers and students have responsibility of co-operating and working together to achieve success and overcome any problems students face during the learning and teaching argumentative writing process, and teachers have to identify the problems that students suffer from to direct and support them through using creative and appropriate methods that enable students to produce well-organized and well-written essays. Hence, the researchers of the current study discussed the problems that students face of level seven during advanced writing course and identified the common errors that the majority of the students committed during writing argumentative essay. A follow-up-interview was folded with the students through using open-end questions. The interview consisted of (10) questions to identify exactly the problems, their responses were taken and the results proved that $90 \%$ of the students suffered crucial problems such as difficulty in expressing ideas in English, using Arabic translation to transform ideas into English language which caused grammatical mistakes, difficulties in finding enough ideas, difficulty in brainstorming, problems with the organization of the ideas in logical orders, lack of consistency among paragraphs, lack in using supporting examples, and a lot of mistakes in grammar, punctuation and spelling.

All of these problems may be related to the method, duration and the amount of credit hours that they were receiving at English department, at Shaqraa University. Students just study four courses of writing during the eighth levels or till graduation, composition one which is writing basics, composition two which focused on paragraph writing students receive training for writing long and short types of paragraphs, writing essay at level four especially narrative and descriptive essay then, students stop taking courses on writing at level five and six and take advanced writing course at level seven focusing on argumentative essay. Because of this gap students suffered a lot of complex problems and difficulty in training again. Hence, teacher has to use modern strategies to enable his students to write smoothly and effectively.

There are many modern techniques for teaching materials as adaptive e-learning, active and flipped learning. The researchers sought the proper method of teaching argumentative essay to compensate the weakness in students' levels. The researchers chose adaptive learning to help students to improve their writing performance. Adaptive learning was used as a strategy, through its tech- 
niques students received enough training during the stages of writing argumentative essay. Adaptive learning is a type of technological learning that support students with different learning experience to master the context of courses through continuous feedback based on students' responses to follow up the course skills. Adaptive learning allows achieving resiliency among the students, the course, the instructor and integrate all the course materials. Computers and internet access were used to practice argumentative writing activities according to students needs, experiences, tasks, questions, responses and learning styles. Computer were used to address each learner, exchanging experience, presenting educational context, practicing tasks, and asking and answering questions during the stages of writing argumentative essays according to the given topics suggested by the instructor. Adaptive learning focused on individual differences among the students and adapted the method of teaching in the light of these differences to establish a positive learning to each student in a very limited time and achieve the best results to improve students' performance.

\section{Statement of the Problem}

Level seven students in the English Department, at shaqra' University, Kingdom of Saudi Arabia suffer problems and difficulties in writing argumentative essay.

\section{Research Questions}

1) What are the effects of adaptive learning versus the traditional method adopted by students' writing performance?

2) What are the effects of adaptive learning on students' opinions towards writing argumentative essay course?

\section{Hypothesis of the Study}

1) There are no significant differences at 0.05 level among the adjusted mean scores attained by the study groups in the post-test of advanced writing due to adaptive learning.

2) There are no significant differences at 0.05 level among the adjusted mean scores attained by the study groups due to students' opinions on adaptive learning.

\section{The Significance of the Study}

The present study tackled major problems facing students at English department during writing argumentative essays. It helped teachers and students to understand more about the adaptive learning techniques. Assessing students through the use of adaptive learning techniques reinforced their performance, identifying strengths and weaknesses and supporting students move forward. The study also gave opportunity to the students to evaluate the techniques used during the experiment. 


\section{Theoretical Background}

\subsection{Adaptive Learning Related-Studies}

Adaptive learning is online data-based techniques used to, improve, edit and support teaching and learning processes to access students' performance. The procedural definition of the present study is the techniques used by both teachers and students based on "computer and on-line data" to improve and support students' performance during writing argumentative essay. Gohar \& El-Ghool, 2016 referred to adaptive learning as a personalized system that meets the learners needs and abilities based on a strategy that support and help students to overcome their problems, also Khamis (2015) defined adaptive learning as the capacity of the e-learning system to provide and support learners with instructional needs to deliver the right content, student, and suitable time and also to present a flexible and varied materials for monitoring and accommodating the teaching and learning strategies. Oxman \& Wong (2014) defined adaptive learning as a process through which the students learn the content based on personalized goals that help to learn and assess these goals in continuous basis using technological systems to improve or accelerate a student's performance.

Adaptive learning is considered as one of the modern trends in teaching materials and it can overcome the problems of the traditional method, few studies investigated the interference between adaptive learning and other language skills. A Research paper was conducted by Khoo et al. (2019) aimed to exploring the effect of adaptive learning strategies in enhancing student engagement. By using adaptive learning with gamification. The participants involved in this study were seventy undergraduate students from Malaysia. The results showed that adaptive learning motivated students to learn more and improved their knowledge it also enhanced Students' engagement.

A Research investigated by Catalan (2019) examined the effectiveness of online adaptive learning technologies on Students' learning and performance. The participants consisted of students in two different, senior-level courses in the mid-western university. The results showed that OALT had a positive influence on students and increased their performance and they felt more engaged in classroom activities.

In addition to, a study was conducted by Zarrabi \& Bozorgian (2020) aimed to exploring students' online argumentative writing performance consisted of (72) undergraduate male and female students. The results showed that students who used between-word or between-sentence pause strategy (PS), active writing plus planned pause showed better OAWP than the other students who used different strategies.

A study by Coffin and Pérez (2015) aimed to comparing the effectiveness of the adaptive learning method and the traditional objective evaluation method. The participants were 218 students from many different majors and at various levels. The results of this study revealed that students learning by the two methods showed no significant differences both of them are efficient. 
Few studies referred to the importance of adaptive learning in teaching writing such as Allen \& McNamara (2016) who asserted the value of integrating adaptive learning platforms into robust writing courses, and indicated the crucial role of computer-based writing instruction in improving writing instruction, extending research on writing development, contributing to writing instructors' professional development, supporting students with sustained strategies and overcoming the limitations of traditional methods. Similarly, Allen \& McNamara (2016) emphasized that computer-based writing instruction should have application in teaching and learning processes, and teachers have to use their own adaptive learning platforms.

\subsection{Argumentative Essay Related-Studies}

The procedural definition of the present study is the ability of the student to argue for or argue against certain issue using a rational method depending on adaptive learning to enrich and expand students' information during the stages of composing process focusing on content, organization and mechanics of writing.

Scholars and specialists examined the difficulties and problems in writing process, (Özdemir, 2018; Öztürk, 2016) concluded that the majority of the students from different ages and levels suffered troubles during writing argumentative essays, they also stated that $93 \%$ of the students write irrelevant data and unable to argue the topic, and disorderly and poorly develop the essay. Midgette \& Haria, 2016; Du, 2017 determined the problems that face students during writing argumentative essay such as lack of coherence and sustainability during writing, poor support for the thesis statement, mistakes in the mechanics of writing. The present study also, identified the common reason to the complex skills that required to produce essay, so that students have to master variety of variables and receive enough training to achieve a advanced levels. There are a few studies that explored the students' problems in advanced writing especially, argumentative essay. A study was conducted by Latifi et al. (2019) aimed to examining the effects of unscripted, scripted and guided online peer feedback on students' argumentative essay writing, Participants were 52 students. The results showed that online peer feedback improved the quality of the students' argumentative essay.

A related research paper was conducted by Wambsganss et al. (2020) aimed to exploring the impact of adaptive learning on Students' argumentation skills, by inventing an adaptive IT tool based on continued user feedback, It consisted of 54 students. The results showed that adaptive learning helped in improving students writing and motivated them to write more convincing texts.

Similarly, Ka-Kan-Dee \& Kaur (2014) examined the difficulties which students face during writing argumentative essay by using think-aloud protocol. the study sample consisted of 60 participants of Thai English language learners. The results indicated that that providing the teachers with precise information of student's weaknesses can help them to support students and help them to overcome their weaknesses during writing argumentative essay. 
Setyowati, Sukmawa, \& Latief (2017) investigated a related research concerned with students' problems in writing argumentative essay, and what are the best methods that can help students to solve their problems in argumentative writing by using planning strategies. The participants of this study were 18 Indonesian English language students. The result shows that the different planning strategies were all equally efficient and helped in developing students' argumentative writing performance.

Related research was conducted by Wulan Rahmatunisa (2014). The study examined the problems which were faced by some EFL students in writing argumentative essay. The participants were the second year of EFL major students. The results of the data show that students faced problems in three categories of language.

\section{Materials and Methods}

\subsection{The Experimental Design of the Study}

The present study adopts the quasi-experimental design, the sample choice was purposive sample, representing one group worked as control and experimental. The participants consisted of 36 students chosen from seven level students included the total of the class, at English department, Faculty of Science \& Humanities, Shaqra' University. The study sample participated in piloting the experimental and control groups. The treatment was given to the same group to enhance the students' advanced writing (argumentative essay).

\subsection{The Participants of the Study}

Thirty six female students presenting the total class of level seven, English department, Shaqra' University. The participants were assigned to answer the pre-post tests and participated in the follow-up interview and piloting of the questionnaire. The sample age was between $21-22$. They have the same impressions and opinions. All of them study the course for the first time. There were no repeaters in the course. The sample of the study was purposively selected. The participants were provided by enough information concerning the experiment, the tools used, their duties, the stages of the experiment, the ways of evaluation, and their rights if they want to withdraw. All of the participants agreed on the experiment, all of them were motivated to try the suggested method to meet their needs and expectations.

\subsection{The Instruments of the Study were}

1) A follow-up interview

2) The pre-post advanced writing test to compare the effect of adaptive learning technique.

3) Adaptive learning questionnaire

4) Argumentative essay writing test:

In order to measure the effect of adaptive learning on improving students 
performance on writing argumentative essay the researchers designed a pre-test to measure the students level after six weeks of teaching using traditional methods and before using adaptive learning. The post-test was given to the experimental group at the end of the experiment after fourteenth week. The test was used to evaluate the students' argumentative essay writing comparing the results after using traditional method and using of adaptive learning.

\subsection{Validity and Reliability of Argumentative Essay Test}

The test was presented to two professors specialized in TEFL to elicit their comments and suggestions. Comments and suggestions of the professors were taken into consideration when making the last versions of the test. The reliability coefficient of the advanced writing test was determined using SPSS. Table 1 shows that Pearson correlation coefficient computed of the $1^{\text {st }}$ and the $2^{\text {nd }}$ tests were 0.976 which is significant at 0.01 level. It also showed that the Cronbach's Alpha of These tests was 0.815 which indicated that the test was of high reliability making it ready for administration.

\subsection{Adaptive Learning Questionnaire}

In order to assess and identify the strong and weak points in the adaptive learning techniques; students were given a questionnaire to give their opinion towards the techniques used during writing argumentative essay The questionnaire consists of a list of (14) characteristics of adaptive learning. The students indicate the degree to which they believe for each of these items by marking whether they (5) strongly agree, (4) agree, (3) neutral, (2) disagree, or (1) strongly disagree that it applies. There are no rights or wrong answers.

\subsection{Validity and Reliability of the Questionnaire}

The questionnaire was presented to two professors specialized in TEFL to elicit their comments and suggestions. The reliability coefficient of the questionnaire was determined using SPSS. Table 2 showed that Cronbach Alphab was (0.819) which is significant at 0.01 which meant that the questionnaire was of high reliability making it ready for administration.

Table 1. Pearson correlation coefficient for pre-post reliability.

\begin{tabular}{cccc}
\hline pre & Corrected Item-Total Correlation & $0.976^{* *}$ & Cronbach's Alpha \\
& $\mathrm{N}$ & 36 & \\
post & Corrected Item-Total Correlation & $0.976^{* *}$ & 0.815 \\
& $\mathrm{~N}$ & 36 & \\
\hline
\end{tabular}

Table 2. Cronbach's Alpha for the questionnaire reliability.

\begin{tabular}{ccc}
\hline \multicolumn{3}{c}{ Reliability Statistics } \\
\hline Cronbach's Alpha & N of Items \\
\hline .819 & 14 \\
\hline
\end{tabular}




\subsection{Teaching Procedures}

The duration of the present experiment lasted for seventeen weeks in the first semester for the academic year 2019/2020. There were two teaching phases in the present study. The first phase teachers followed the traditional method in teaching based on classroom direct instruction in the light of sustained feedback for seven weeks then the students carried out the pre test at eighth week. The second phase, teacher used adaptive learning techniques according to the following table for another eight weeks after the intervention the students received the post test. Table 3 showed the techniques, tasks and materials used in the experiment.

\subsection{The Techniques, Tasks and Materials Are Provided in the Following Table}

Table 3. The techniques, tasks and materials.

\begin{tabular}{|c|c|c|c|c|}
\hline Expert materials & $\begin{array}{l}\text { Students' } \\
\text { material }\end{array}$ & Gamification & $\begin{array}{l}\text { Teacher's } \\
\text { instruction }\end{array}$ & On-line examples \\
\hline $\begin{array}{l}\text { Each student } \\
\text { stored the whole } \\
\text { components of the } \\
\text { course via their } \\
\text { e-mails, teacher } \\
\text { gave them the } \\
\text { instructions and } \\
\text { the covering topics } \\
\text { and distribution of } \\
\text { lesson (during the) } \\
\text { semester. }\end{array}$ & $\begin{array}{l}\text { Each student } \\
\text { made } \\
\text { presentation for } \\
\text { the given topic } \\
\text { using her } \\
\text { personal } \\
\text { computer } \\
\text { presenting it in } \\
\text { class using } \\
\text { projectors and } \\
\text { made discussion } \\
\text { with her } \\
\text { classmates and } \\
\text { teacher }\end{array}$ & $\begin{array}{l}\text { To keep students } \\
\text { engaged in } \\
\text { continuous learning } \\
\text { and make writing } \\
\text { more fun, teacher } \\
\text { chose two ways of } \\
\text { games: } \\
\text { 1) Classbadges } \\
\text { 2) Edublogs }\end{array}$ & $\begin{array}{l}\text { First teacher's } \\
\text { evaluate students' } \\
\text { materials and gave } \\
\text { feedback according } \\
\text { to the level of the } \\
\text { student the teacher } \\
\text { explained lessons } \\
\text { provided them with } \\
\text { different examples. }\end{array}$ & $\begin{array}{l}\text { Both teacher and } \\
\text { students gave } \\
\text { different examples } \\
\text { for introducing the } \\
\text { issue using } \\
\text { YouTube videos } \\
\text { and electronic } \\
\text { articles, students } \\
\text { used } \\
\text { peer-evaluation to } \\
\text { enhance } \\
\text { improvements. }\end{array}$ \\
\hline
\end{tabular}

\section{Presentation of Results and Discussions}

Descriptive and inferential statistics were used to test this hypothesis. What are the effects of adaptive learning versus the traditional method adopted by students' writing performance? Table 4 shows descriptively the differences between the mean scores attained by the study groups in the posttest of advanced based on adaptive learning.

Table 4. Descriptive Statistics of the pre-post test.

\begin{tabular}{|c|c|c|c|c|c|}
\hline \multicolumn{6}{|c|}{ Descriptive Statistics } \\
\hline & & Mean & $\mathrm{N}$ & $\begin{array}{c}\text { Std. } \\
\text { Deviation }\end{array}$ & $\begin{array}{l}\text { Std. Error } \\
\text { Mean }\end{array}$ \\
\hline \multirow{2}{*}{ Pair 1} & Grades after applying adaptive learning & 80.25 & 36 & 12.984 & 2.164 \\
\hline & Grades after applying traditional method & 43.08 & 36 & 5.353 & .892 \\
\hline
\end{tabular}


The Mean for the pre-test after applying traditional method was 43.08 that described the student's grades before applying adaptive learning techniques. The Mean for the post test is 80.25 that indicated a noticeably increase in the means. The standard deviation showed 5.353 before applying traditional method and after applying learning the adaptive learning method equals 12.984 .

\section{Normality tests:}

The K-S test for normality, results indicated that the distribution of variables were not normally distributed, $\mathrm{p}$. value equal 0.001 respectively less than alpha 0.05 (Table 5).

As for p. value for Wilcoxon test equal 0.000 less than significant level alpha 0.05 , it means rejecting of $\mathrm{H} 0$. The results indicated that there is a significant differences at.05 level among the mean scores attained by the study groups in the post test of argumentative essay due to adaptive learning (Table 6, Table 7).

Descriptive and inferential statistics were used to test this hypothesis: What are the effects of adaptive learning on students' opinions? Table 8 shows descriptively the differences between the mean scores attained by the study groups in response to the questionnaire to evaluate the techniques based on adaptive learning. As for $\mathrm{p}$. value for normality the K-S test equal ( 0.000 respectively less than alpha 0.05 in all the items of the questionnaire which indicated that the distribution was not normal. The means are arranged in descending order.

Table 5. Kolmogorov-Smirno Tests of Normality.

\begin{tabular}{lccc}
\hline & \multicolumn{3}{c}{ Tests of Normality } \\
\cline { 2 - 4 } & \multicolumn{3}{c}{ Kolmogorov-Smirnov $^{\mathbf{a}}$} \\
\cline { 2 - 4 } & Statistic & df & Sig. \\
\hline Grades before applying adaptive learning & 0.195 & 36 & 0.001 \\
Grades after applying adaptive learning & 0.198 & 36 & 0.001 \\
\hline
\end{tabular}

Table 6. Wilcoxon signed ranks test non-parametric Wilcoxon signed ranks test.

\begin{tabular}{|c|c|c|c|c|}
\hline \multicolumn{5}{|c|}{ Ranks } \\
\hline & & $\mathbf{N}$ & Mean Rank & Sum of Ranks \\
\hline \multirow{4}{*}{ Post-pre } & Negative Ranks & $0^{\mathrm{a}}$ & 0.00 & 0.00 \\
\hline & Positive Ranks & $36^{\mathrm{b}}$ & 18.50 & 666.00 \\
\hline & Ties & $0^{c}$ & & \\
\hline & Total & 36 & & \\
\hline
\end{tabular}

Table 7. Wilcoxon test statistics.

\begin{tabular}{cc}
\hline \multicolumn{2}{c}{ Test Statistics $^{\mathrm{a}}$} \\
\hline $\mathrm{Z}$ & post-pre \\
\hline Asymp. Sig. (2-tailed) & -5.23 - $^{\mathrm{b}}$ \\
\hline
\end{tabular}


Table 8. Descriptive Statistics of the adaptive learning questionnaire.

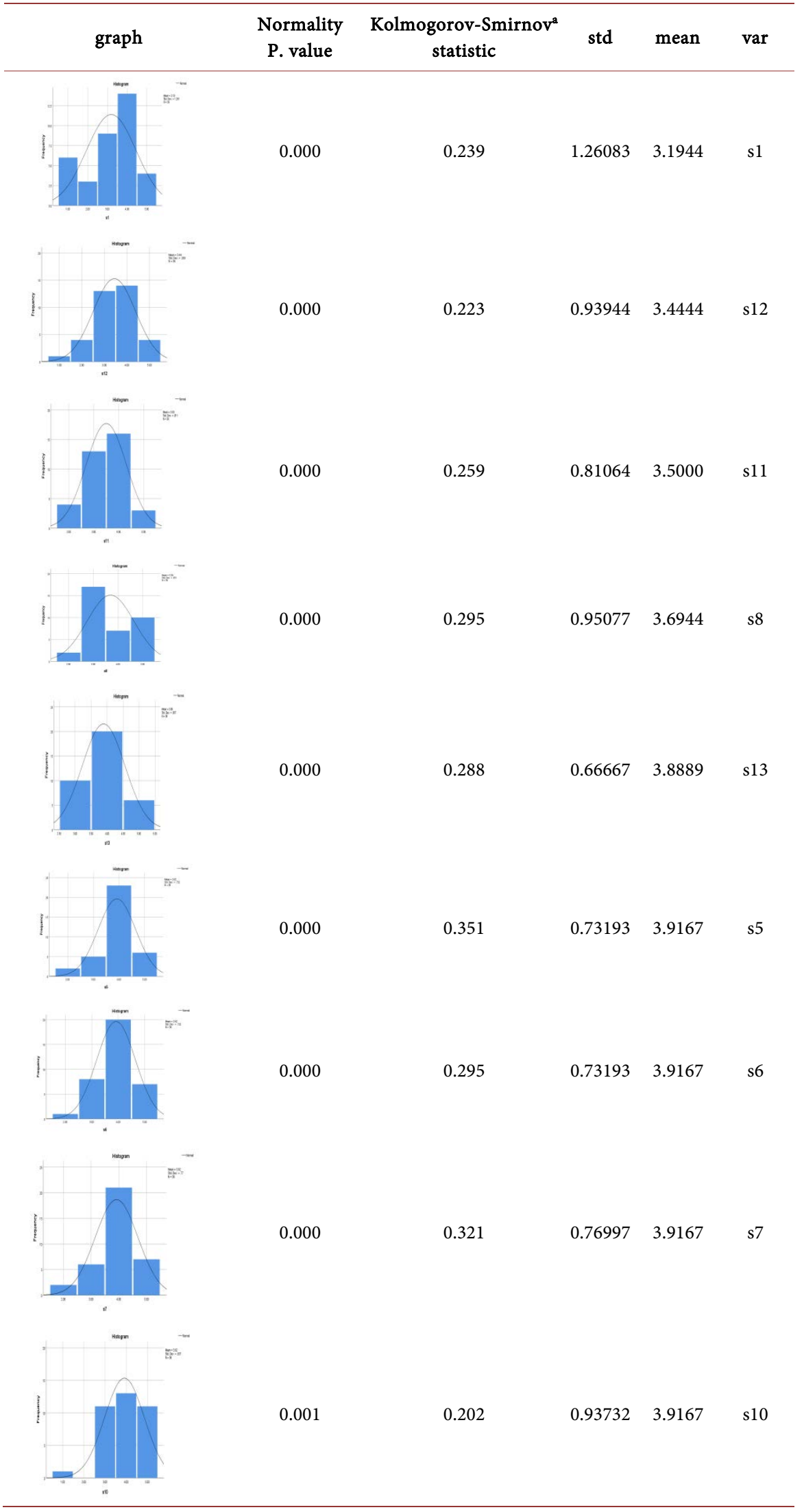




\section{Continued}

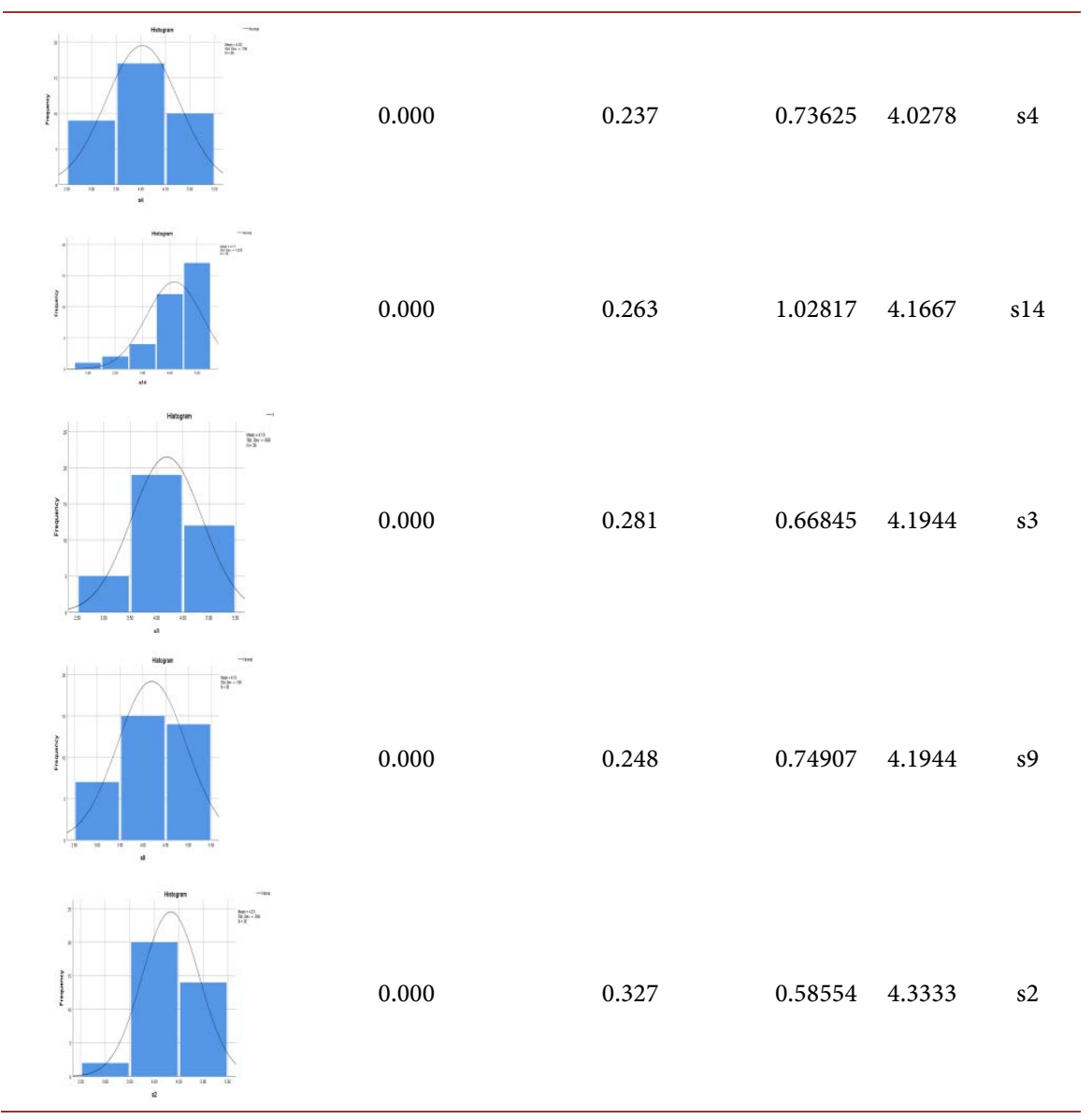

The frequencies variables statistical results of the questionnaire of adaptive learning revealed that the lowest ones were s1 "My teachers used adaptive learning before in different courses." $(\mathrm{M}=3.1944)$, sig. $=\left(0.709^{\star}\right)$, the second item was $\mathrm{s} 12$ "I had a competitive spirit during the application of adaptive learning " $\mathrm{M}$ $=(3.44445)$, sig. $=\left(0.878^{\star}\right)$ the third item was s11" Oral and visual presentations varied my style of writing $(M=3.5000)$, sig. $=\left(0.031^{\star}\right)$ Whereas, the highest items were for s2" I had a desire to apply adaptive learning in writing argumentative essay $(\mathrm{M}=4.3333)$, sig. $=\left(000^{*}\right)$; and the second one was $\mathrm{s} 9$ "videos and on-line tasks helped me to argue for and against" $(M=4.1944)$, sig. $=\left(0.114^{*}\right)$. The third one was S3 "the techniques of adaptive learning helped me to organize my ideas during arguing $(M=4.19440)$, sig. $=\left(0.394^{\star}\right)$ ". The results of the questionnaire indicated that the students were capable of achieve improvement in their performance in writing related to their first use of adaptive learning, the techniques used and also have positive attitude towards the course which means rejecting of $\mathrm{HO}$ and there were significant differences at 0.05 level among the adjusted mean scores attained by the study group due to students' opinions on adaptive learning.

\section{Conclusion}

The present study tackled major problems facing students at English department 
during argumentative essay writing and examined the effect of adaptive learning on improving students' argumentative essay writing. The researcher identified students' strengths and weaknesses points through a follow-up interview, and supported them to improve their performance and move forward using adaptive learning techniques. The researcher assessed the techniques used during teaching the course through a questionnaire given to students. Based on the findings of the study, the quantitative and qualitative results concluded that adaptive learning technique proved to be effective in enhancing students' argumentative essay writing at Shaqra' University and beneficial for developing students' performance in writing. Students' response to the questionnaire indicated that they didn't receive such type of training before and never made previously between e-learning and classroom learning and they had positive attitude towards the course related to adaptive learning techniques.

\section{Educational Implication}

The results of the present study may be benefit for teaching students how to write argumentative using modern methods. Adaptive learning can be used in teaching and learning other courses such as oral skills, literature and linguistics courses.

\section{Recommendation for Further Research}

In the light of the present study results, providing students with the modern and recent techniques is essential and critical to improve their performance during writing argumentative essay also, writing instructions should be given more attention in our EFL classes. Moreover, integrating adaptive learning platforms into writing courses is very important to enhance argumentative essay main skills and its sub-skills. Technicalities that used in adaptive learning should be stressed in the preparation programs of English language teachers so that, they will be capable of training their students to write effectively. Students' common errors in writing argumentative essays should be surveyed, discussed and remedied though different types of training programs to help them overcome their difficulties and improve their overall writing performance. Further studies needed to be investigated to examine the effect of adaptive learning on enhancing language accuracy and fluency.

\section{Conflicts of Interest}

The authors declare no conflicts of interest regarding the publication of this paper.

\section{References}

Allen, L. K., \& McNamara, D. S. (2016). Computer-Based Writing Instruction. In C. J. MacArthur, S. Graham, \& J. Fitzgerald (Eds.), Handbook of Writing Research (2nd ed., pp. 316-330). New York: Guilford. 
Catalan, D. (2019). An Examination of the Effectiveness of Online Adaptive Learning Technologies. The Accounting Educators' Journal, 29, 61-80.

Coffin, M., \& Pérez, J. (2015). Informing and Performing: A Study Comparing Adaptive Learning to Traditional Learning. Informing Science: The International Journal of an Emerging Transdiscipline, 18, 111-125. https://doi.org/10.28945/2165

Du, F. (2017). The Analysis of Argument-Counterargument Structure in Chinese EFL Learners' Argumentative Writing. Journal of Studies in Education, 7, 121-129. https://doi.org/10.5296/jse.v7i3.11275

Gohar, R. H., \& El-Ghool, R. M. (2016). Designing an Adaptive Learning Environment to Improve Writing Skills and Usability for EFL Students at the Faculty of Education. International Journal of Internet Education, 15, 63-93. https://doi.org/10.21608/ijie.2016.3682

Ka-Kan-Dee, M., \& Kaur, S. (2014). Argumentative Writing Difficulties of Thai English Major Students (pp. 193-207). The 2014 WEI International Academic Conference Proceedings.

Khamis, M. A. (2015). Adaptive E-learning Environment Systems and Technologies. Albaha, KSA: The First International Conference of the Faculty of Education, Albaha University.

Khoo Mei Sui, L. et al. (2019). Adaptive Learning Strategies with Gamification to Enhance Learning Engagement. Indian Journal of Science and Technology, 12, 348-353.

Midgette, E., \& Haria, P. (2016). Planning and Revising Written Arguments: The Effects of Two Text Structure-Based Interventions on Persuasiveness of 8th-Grade Students' Essays. Reading Psychology, 37, 1043-1075. https://doi.org/10.1080/02702711.2016.1159631

Oxman, S., \& Wong, W. (2014). White Paper: Adaptive Learning Systems. Integrated Education Solutions.

Ozdemir, S. (2018). The Effect of Argumentative Text Pattern Teaching on Success of Constituting Argumentative Text Elements. World Journal of Education, 8, 112-122. https://doi.org/10.5430/wje.v8n5p112

Öztürk, D. (2016). A Research on Argumentative Text Writing Skills of Teacher Candidates. Unpublished Master's Thesis, Malatya, Turkey: Inonu University.

Setyowati, L., Sukmawa, S., \& Latief, M. (2017). Solving the Students' Problems in Writing Argumentative Essay through the Provision of Planning. A Journal of Culture, English Language Teaching \& Literature, 17, 86-102. https://doi.org/10.24167/celt.v17i1.1140

Setyowati, Sukmawa, S., \& Latief, M. (2017). How Does Online Peer Feedback Improve Argumentative Essay Writing and Learning. Innovations in Education and Teaching International, 55, Article ID: 102546.

Wambsganss, T. et al. (2020). An Adaptive Learning Support System for Argumentation Skills. ACM CHI Conference on Human Factors in Computing Systems.

Wulan, R. (2014). Problems Faced by Indonesian EFL Learners in Writing Argumentative Essay. Journal of English Education, 3, 41-49.

Zarrabi, F., \& Bozorgian, H. (2020). EFL Students' Cognitive Performance during Argumentative Essay Writing. Computers and Composition, 55, Article ID: 102546.

https://doi.org/10.1016/j.compcom.2020.102546 